SOI: $1.1 /$ TAS $\quad$ DOI: $10.15863 /$ TAS

International Scientific Journal Theoretical \& Applied Science

p-ISSN: 2308-4944 (print) $\quad$ e-ISSN: 2409-0085 (online)

Year: 2017 Issue: $01 \quad$ Volume: 45

Published: $30.01 .2017 \quad \underline{\text { http://T-Science.org }}$

SECTION 4. Computer science, computer engineering and automation.
Andrei Mastislavovich Korneev

Doctor of Technical Sciences, Professor, director of the institute of Lipetsk State Technical University, Russia, Lipetsk

Olga Petrovna Buzina

Candidate of Technical Sciences, Associate Professor, head of the department of Lipetsk State Technical University, Russia, Lipetsk

Andrei Vladimirovich Sukhanov postgraduate student, assistant of Lipetsk State Technical University, Russia, Lipetsk pm03sav@mail.ru

Ilya Andreevich Shipulin postgraduate student, assistant of Lipetsk State Technical University, Russia, Lipetsk shipulin-ilya@yandex.ru

Nikita Andreevich Shipulin student of Lipetsk State Technical University, Russia, Lipetsk

\title{
ALGORITHM FOR ESTIMATING THE INITIAL RELIABILITY OF ELEMENTS DISPERSED STRUCTURE WITH A DISCRETE FIBER ON THE BASIS OF PROBABILITY MATHEMATICAL MODEL
}

\footnotetext{
Abstract: The article describes the main provisions of probabilistic mathematical model to assess the reliability of bent elements, steel-reinforced dispersion-discrete fibers with a single limb at both ends ("Dramix»). The authors, based on a mathematical nonlinear deformation model developed probabilistic algorithm and a computer program to assess the reliability of fiber concretes beams, flexural, taking into account physical nonlinearity of materials, which implements the method of statistical modeling. Probability calculation is to determine the statistical characteristics of strength, stiffness and fracture study design elements during a large number of statistical tests associated with modeling initial random quantities - prism strength matrix ultimate strength tensile fibers, the angle of orientation of the fibers and their incorporation. As a result, the program outputs the reliability indexes bent elements, reinforced with steel discrete fibers for strength, stiffness and fracture toughness. These figures allow us to judge about the serviceability of the study of structural elements.

Key words: probabilistic mathematical model, statistical modeling method, random variable, discrete fiber, reliability of the design element.

Language: English

Citation: Korneev AM, Buzina OP, Sukhanov AV, Shipulin IA, Shipulin NA (2017) ALGORITHM FOR ESTIMATING THE INITIAL RELIABILITY OF ELEMENTS DISPERSED STRUCTURE WITH A DISCRETE FIBER ON THE BASIS OF PROBABILITY MATHEMATICAL MODEL. ISJ Theoretical \& Applied Science, 01 (45): 89-92.

Soi: http://s-o-i.org/1.1/TAS-01-45-18 Doi: crossef https://dx.doi.org/10.15863/TAS.2017.01.45.18

\section{Introduction}

Construction of non-homogeneous material, in particular, reinforced with discrete fibers, should be provided with the required reliability of the occurrence of all types of limit states calculation, choice of indicators of quality of materials, size and purpose of the construction according to the instructions.

The influence of technological factors and their variability in the structural reliability can be made

only by means of probability calculations that take into account the interaction of random variables hence the development of a probabilistic algorithm is one of the main tasks in the organization of the quality control of its products. In addition, the development of probabilistic algorithms and the writing on the reliability of the evaluation program of structural elements necessary to carry out numerical simulations to study the effect of the variability of different technological factors on their usability.
} 


\begin{tabular}{|c|c|c|c|c|c|c|}
\hline Impact Factor: & $\begin{array}{l}\text { ISRA (India) } \\
\text { ISI (Dubai, UAE } \\
\text { GIF (Australia) } \\
\text { JIF }\end{array}$ & $\begin{array}{l}=1.344 \\
=0.829 \\
=0.564 \\
=1.500\end{array}$ & $\begin{array}{l}\text { SIS (USA) } \\
\text { PИНЦ (Russia) } \\
\text { ESJI (KZ) } \\
\text { SJIF (Morocco) }\end{array}$ & $\begin{array}{l}=0.912 \\
=0.234 \\
=1.042 \\
=2.031\end{array}$ & $\begin{array}{l}\text { ICV (Poland) } \\
\text { PIF (India) } \\
\text { IBI (India) }\end{array}$ & $\begin{array}{l}=6.630 \\
=1.940 \\
=4.260\end{array}$ \\
\hline
\end{tabular}

\section{Materials and Methods}

The underlying automated control of a probabilistic assessment of the reliability of the initial carried out at the time of completion of the process of manufacturing cycle and coincides in time with the transmission of forces with reinforcements on the concrete. On subsequent behavior design technological factors have no effect. Evaluation using statistical characteristics resulting from every shift process control.

Test structures provide an opportunity to assess their suitability for multiple groups of limit states: strength, rigidity and crack resistance. Accordingly, as the main criteria in assessing the operational suitability $[1,2,3]$ bent elements shall, as a rule, the following indicators:

a) strength fiber concrete (average value of the load $F$ in the tests should not be below the specified maximum load $F_{u l t}$ ):

$$
H_{0}=\frac{1}{2}\left(1+\Phi\left(\frac{\bar{F}-F_{u l t}}{S_{F}}\right)\right)
$$

b) stiffness (mean value of deflection $f$ bending element must not exceed the critical $f_{u l t}$ ):

$$
H_{1}=\frac{1}{2}\left(1+\Phi\left(\frac{f_{u l t}-\bar{f}}{S_{f}}\right)\right)
$$

c) fracture toughness (the mean value of the crack opening in the central normal section bending element $a_{c r c}$ should not exceed the critical value $\left.a_{c r c, u l t}\right)$ :

$$
H_{2}=\frac{1}{2}\left(1+\Phi\left(\frac{a_{c r c, u l t}-\bar{a}_{c r c}}{S_{a}}\right)\right) .
$$

$S_{F}, S_{f}, S_{a}-$ standard deviations, respectively, the quantities $F, f, a_{c r c} ; \Phi(\mathrm{x})$ - Laplace function:

$$
\Phi(x)=\frac{2}{\sqrt{2 \pi}} \int_{0}^{x} e^{-t^{2} / 2} d t .
$$

An important issue is the appointment values $H_{0}, H_{l}, H_{2}$, determine the material consumption designs. Based on the calculation of the strength characteristics of the materials specified in the design standards for steel fiber reinforced designs, reliability levels for each limit state varies from 0.8 to 0.98 , depending on the operating conditions (temperature, humidity, aggressive media and others.) and structures of responsibility. According to $[1,4,5]$ can be taken as required by the following values of $H_{0}=$ $0,95, H_{l}=0,95, H_{2}=0,90$.

Most theoretical studies [6] to assess the reliability reinforced concrete structures show that the most effective methods for developing algorithms are probabilistic methods: linearization functions, statistical modeling, statistical tests.

When using the method of statistical modeling [7] made a sufficiently large number $(n=10000 \ldots$ 30000) statistical tests of the Bernoulli scheme, each test is randomly generated the realization of all the initial values according to their probability density functions. As an independent random variables in a program to assess the reliability of flexible dispersion-reinforced components at the manufacturing stage adopted: the strength of the composite matrix, the strength of the discrete fiber initial modulus composite matrix of elasticity, the sectional area of the fibers, the geometrical characteristics of the cross section of a flexible element, the orientation of discontinuous fiber in the matrix composite anchoring discrete fibers (their normal position relative to the central section). All the characteristics of a normal distribution [7].

When you play random variables on a computer using a standard function $\operatorname{rand}(\mathrm{x})$ to generate random numbers uniformly distributed in the range $[0 ; 1]$; To obtain random numbers from a normal distribution with mathematical expectation $M=0$ and variance $D$ $=l$ can be used, depending on the following:

$$
\left\{\begin{array}{l}
\xi_{1}=\sqrt{-2 \ln \gamma_{1}} \cdot \cos \left(2 \pi \gamma_{2}\right) \\
\xi_{2}=\sqrt{-2 \ln \gamma_{1}} \cdot \sin \left(2 \pi \gamma_{2}\right)
\end{array}\right.
$$

where $\gamma_{1}, \gamma_{2}$-two independent random numbers with uniform distribution; $\xi_{1}, \xi_{2}-$ two conjugate numbers with normal distribution $(M=0$ and variance $D=1)$.

For initial random variables with a specific value of $D$ and $M$ and recalculated by the formula:

$$
\xi^{\prime}=M+\sqrt{D} \cdot \xi_{i} .
$$

Further taking into account the initial values obtained for the main, the mathematical model is made $N$ times deterministic calculation, calculation of elements on the concrete strength, deflection calculation and width of cracks. Comparison of bearing capacity with the current efforts in the bending element defines one of the possible states of the system as a whole. Statistical analysis of the aggregate of such conditions, the number of which is measured in tens of thousands, it allows you to make appropriate forecasts. For this purpose, statistical processing subroutine defined statistical characteristics of the above values using the following formulas: 


\begin{tabular}{|c|c|c|c|c|c|c|}
\hline Impact Factor: & $\begin{array}{l}\text { ISRA (India) } \\
\text { ISI (Dubai, UAF } \\
\text { GIF (Australia) } \\
\text { JIF }\end{array}$ & $\begin{array}{l}=1.344 \\
=0.829 \\
=0.564 \\
=1.500\end{array}$ & $\begin{array}{l}\text { SIS (USA) } \\
\text { PИНЦ (Russia) } \\
\text { ESJI (KZ) } \\
\text { SJIF (Morocco) }\end{array}$ & $\begin{array}{l}=0.912 \\
=0.234 \\
=1.042 \\
=\mathbf{2 . 0 3 1}\end{array}$ & $\begin{array}{l}\text { ICV (Poland) } \\
\text { PIF (India) } \\
\text { IBI (India) }\end{array}$ & $\begin{array}{l}=6.630 \\
=1.940 \\
=4.260\end{array}$ \\
\hline
\end{tabular}

$$
\begin{gathered}
M(X)=\bar{X}=\frac{\sum_{i=1}^{N} X_{i}}{N} ; D(X)=M(X-M(X))^{2} \\
S(X)=\sqrt{D(X)} ; V(X)=\frac{S(X)}{M(X)}
\end{gathered}
$$

Where $X$ - a random variable; $M(X)$ - the mean value (expectation) of a random variable; $N$ - the number of tests; $D(X)$ - the variance of the random variable: $S(X)$ - the standard deviation of a random variable; $V(X)$ - the coefficient of variation of a random variable.

For the numerical experiment and for practical use of mathematical models based on probability was created a computer program to assess the stress-strain state fiber concretes beams taking into account physical nonlinearity of constructional materials «SFRC.exe» (certificate of state registration of the computer №2016611439). The program allows you to obtain the stress distribution across the section at each stage of loading, taking into account the effect of eccentricities. The program is implemented according to the standards Regulatory Model design of reinforced concrete structures, which allows you to obtain the bearing capacity of the elements and the width of cracks to tension members with the given geometric and strength characteristics.

The flow charts «SFRC.exe» program segments that are based on analytical relationships [8, 9], presented in $[6,10]$.

The program is written by using algorithmic programming language $\mathrm{C}++$ Builder Version 6.0 (Build 10.155).

Each feature in the program algorithm while its coefficient of variation was played on the $2 \cdot 10^{5}$ times.

Experimental study of strength characteristics of concrete [3] it possible to determine the magnitude of the variation prism strength of concrete $V\left(R_{b}\right)$; for different classes of concrete compositions and the values of the coefficient of variation ranged from $10 \%$ to $16 \%$.

Results $2 \cdot 10^{5}$ enactments prism strength of concrete at the coefficient of variation: $V\left(R_{b}\right)=10 \%$, $V\left(R_{b}\right)=13 \%$ and $V\left(R_{b}\right)=16 \%$ are presented as histograms in Figure 1. The average value of the strength of concrete $R_{b}=29,5 \mathrm{MPa}$. a)
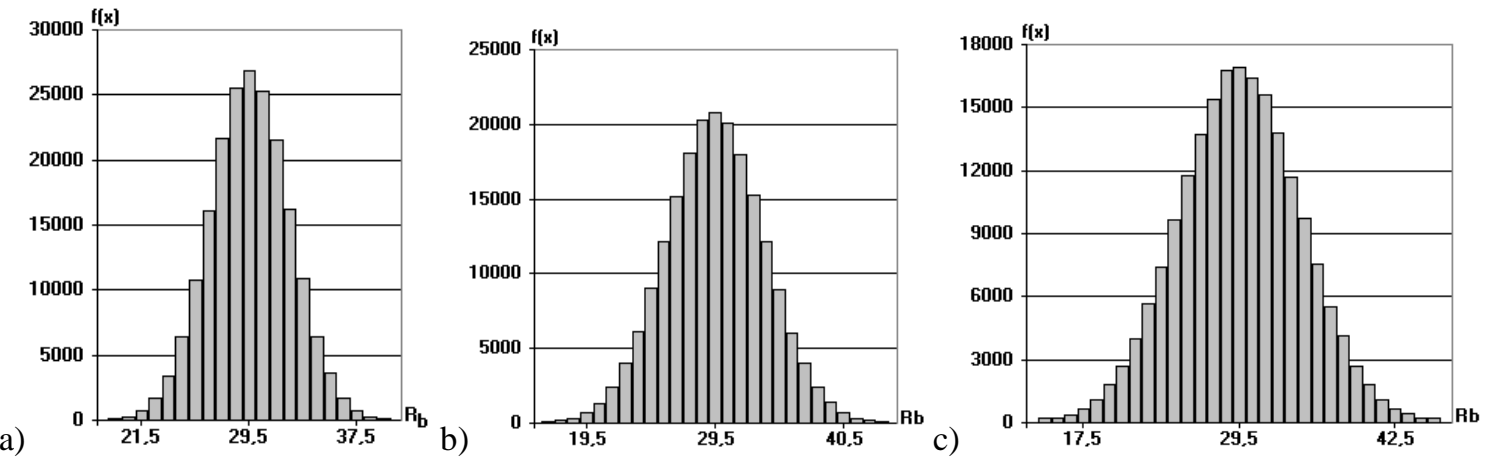

Figure 1 - Histograms concrete strength distribution densities for different coefficients of variation: a) $V=$ $10 \%, b) V=13 \%$, c) $V=16 \%$.

Coefficient of variation of the ultimate strength of the fibers was found to be tensile $V\left(R_{f}\right) \approx 4-8 \%$. Results $2 \cdot 10^{5}$ enactments ultimate strength of the steel fiber in coefficient of variation: $V\left(R_{f}\right)=4 \%$,
$V\left(R_{f}\right)=6 \%$, and $V\left(R_{f}\right)=8 \%$ presented as histograms in Figure 2. The mean value of the ultimate strength of the fibers $R_{f}=1,100 \mathrm{MPa}$.
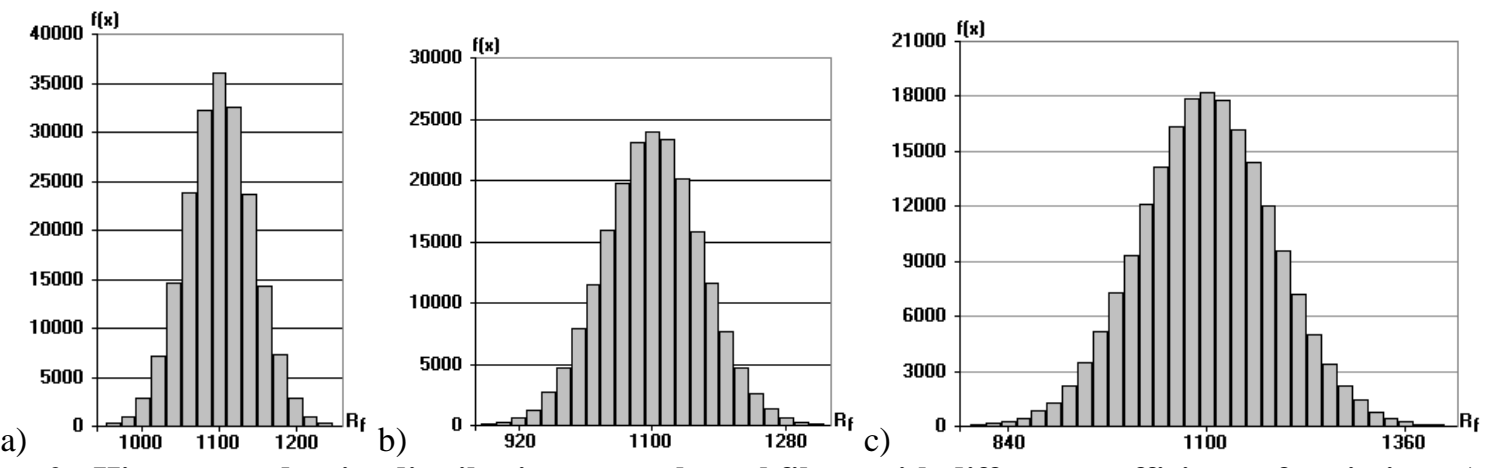

Figure 2 - Histograms density distribution strength steel fibers with different coefficients of variation: a) $V=$ $4 \%$, b) $V=6 \%$, c) $V=8 \%$.

ISPC Perspectives in science for 2017, 
The analysis of experimental samples after field testing fiber-reinforced concrete constructions from [3] allowed us to determine the value of the standard deviation of the angle of orientation of the fibers in the normal section of the sample: $S(\theta) \approx 0,45 \mathrm{rad}$. Fig. 3 shows the results of the first $10^{4}$ enactments discrete fiber orientation angle. The average value of the fiber orientation angle $\theta=0 \mathrm{rad}$.

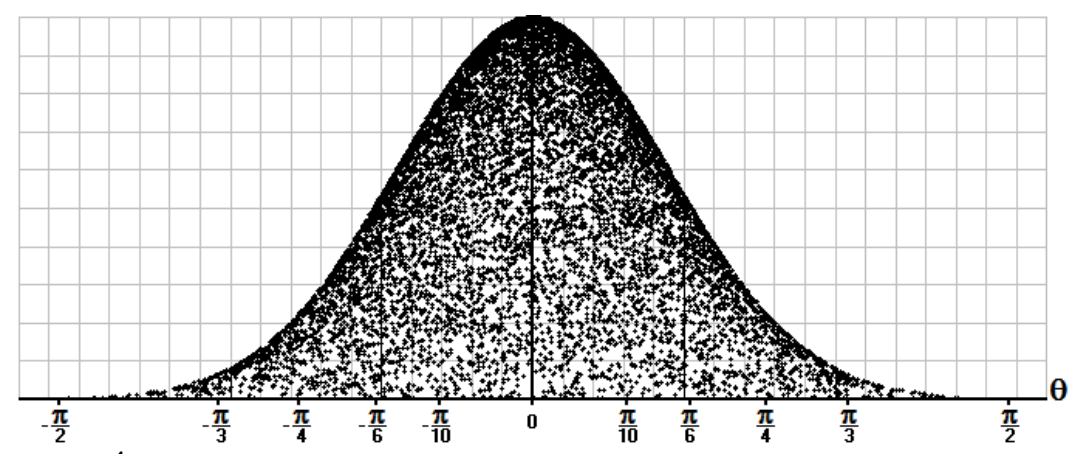

Figure 3 - The first $10^{4}$ results of modeling discrete fiber orientation angle values in the normal section of a flexible element.

\section{Conclusion}

Distribution of the values of the lengths of termination of discrete fibers with respect to the normal section of a flexible element made with an average value of a uniform, equal to $15 \mathrm{~mm}$, and the extremes of 0 and $30 \mathrm{~mm}$.

When comparing the actual and theoretical values of basic statistical characteristics of prism strength of concrete, the strength of the fibers and their orientation and position relative to the normal section of a flexible element, it can be noted that the actual values obtained from the results of numerical modeling, quite close to the theoretical: differences constitute $2-4 \%$.

Designed based on a probabilistic model software system «SFRC.exe» is designed for the analysis of stress-strain state in the normal section of a flexible element - beams on two supports - and assess the reliability of structural elements, working in bending. The program takes into account various combinations of strength properties of the composite matrix volume fraction of discrete fibers and their orientation.

\section{References:}

1. Kovalenko GV (1990) Evaluation of the stressstrain state of ribbed slabs different settlement patterns / G.V. Kovalenko, Y. Samarin, V.M. Mitasov // Proceedings of the universities. Construction and architecture. №11.-p.116-121.

2. Tamarin AA (1967) Test and evaluation of load-bearing properties of the pre-stressed concrete structures / A.A. Tamarin. - M .: Stroyizdat, 1967. - 208 p.

3. Chernousov NN (2010) Bendings stalefibroshlakobetonn elements / N.N. Chernousov, R.N. Chernousov // Concrete and reinforced concrete. - 2010. - № 4. - p. 7-11.

4. Samarin YA (1988) Provisions of reliability and durability of concrete structures prefabricated / Y.A. Samarin, G.V. Kovalenko, M.T. Orlov. M .: INFORMENERGO, 1988. - 44 p.

5. Tamrazyan AG (2001) Ensuring the quality of precast concrete on the stage of manufacture / A.G. Tamrazyan, I.V. Dudin // Housing construction. - 2001. - №3. - p. 8-10.

6. Korneev AM (2016) Probabilistic mathematical model for evaluating the reliability of the initial bent elements, dispersion-reinforced discrete fibers / A.M. Korneev, O.P. Elderberries, A.V. Sukhanov, I.A. Shipulin // Basic Research. 2016. - № 9 (3). - p. 489-494.

7. Spaete G (2013) Die Sicherheit tragender Baukonstruktionen / G. Spaete. - VEB Verlag fur Bauwesen. - Berlin, 2013. - p. 248.

8. Korneev AM (2016) Mathematical modeling and analysis of stress-strain state of inhomogeneous media with continuous and discrete fibers / A.M. Korneev, O.P. Elderberries, A.V. Sukhanov // Fundamental issledovaniya. - 2016. - № 8. - p. 39-44.

9. Korneev AM (2016) Mathematical modeling of mutual influence of steel fibers in the cross section of a flexible element of stalefibroshlakobetona [Text] / A.M. Korneev, O.P. Elderberries, A.V. Sukhanov, I.A. Shipulin // Fundamental issledovaniya. № 4.- p 506-511.

10. Korneev AM (2016) A deterministic mathematical model and algorithm for analysis of stress-strain state of flexible elements with discrete fibers / A.M. Korneev, O.P. Elderberries, A.V. Sukhanov // Modern high technologies. - 2016. - № 9 (1). - p. 57-62. 